\title{
Initial Inflammatory Profile in Community-Acquired Pneumonia Depends on Time since Onset of Symptoms
}

${ }^{1 \#}$ Raúl Méndez MD, ${ }^{1,3}$ Rosario Menéndez MD PhD FERS, ${ }^{2,3}$ Catia Cillóniz PhD, ${ }^{1}$ Isabel AmaraElori MD, ${ }^{2,3}$ Rosanel Amaro MD PhD, ${ }^{1}$ Paula González MD, ${ }^{1}$ Tomás Posadas MD, ${ }^{1}$ Alexandra Gimeno RN, ${ }^{4}$ Pedro P España MD PhD, ${ }^{5}$ Jordi Almirall MD PhD, ${ }^{2,3}$ Antoni Torres MD PhD FERS

Running head: Inflammation and onset of pneumonia symptoms

${ }^{1}$ Pneumology Department, Hospital Universitario y Politécnico La Fe / Instituto de Investigación Sanitaria (IIS) La Fe. University of Valencia. Valencia, Spain.

${ }^{2}$ Pneumology Department, Hospital Clínic / Institut D'Investigacions Biomèdiques August Pi I Sunyer (IDIBAPS). University of Barcelona. Barcelona, Spain.

${ }^{3}$ Centro de Investigación Biomédica En Red-Enfermedades Respiratorias (CIBERES, CB06/06/0028), Madrid, Spain.

${ }^{4}$ Pneumology Department, Hospital de Galdakao-Usansolo. Galdakao, Spain.

${ }^{5}$ Intensive Care Unit, Hospital de Mataró, Barcelona, Spain.

\#PhD program in Medicine and Translational Research. University of Barcelona. Barcelona, Spain.

\section{Corresponding Author:}

Dr. Rosario Menéndez

Servicio de Neumología. Hospital Universitario y Politécnico La Fe, 
Avda. de Fernando Abril Martorell 106, 46026 Valencia. Spain.

E-mail: rosmenend@gmail.com

Dr. Antoni Torres

UVIR, Servei de Pneumologia, Hospital Clínic,

C/ Villarroel 170, 08036 Barcelona, Spain.

E-mail: atorres@clinic.ub.es

Funding/Support: Fondo de Investigación Sanitaria (FIS): 2003/0065; FIS: 2008/0123; Sociedad Española de Neumología y Cirugía Torácica (SEPAR): 2003/0065; SEPAR: 145/2012; Sociedad Valenciana de Neumología (SVN): 2011/0213.

Author's contribution: Conception and design: AT, RM and RaM; Acquisition, analysis or interpretation of data: RaM, CC, IA, RA, PG, TP, AG, PE and JA; Drafting the manuscript for important intellectual content: RaM with assistance from RM and AT; Statistical analysis: RaM and RM; Administrative, technical or material support: RaM, CC, IA, RA, PG, TP, AG, PE and JA; All authors reviewed, revised and approved the manuscript for submission; Study supervision: RM and AT.

\section{Conflict of Interest Disclosures}

All authors declare that they have no conflicts of interest.

Role of the Funder/Sponsor: The funding sources had no role in the design and conduct of the study; collection, management, analysis, and interpretation of the data; preparation, review, or approval of the manuscript; and decision to submit the manuscript for publication. 
Descriptor: 10.12 Pneumonia: Bacterial Infections

Word count: 3118

At a Glance Commentary:

Scientific Knowledge on the Subject:

A correct interpretation of the inflammatory response at diagnosis of community-acquired pneumonia (CAP) can improve initial assessment of severity, management and prediction of outcome. So far, evaluation of initial inflammatory cytokines and biomarkers is performed without considering time since onset of symptoms, which could modify systemic biomarkers levels depending on its own kinetics and the phase of infection.

\section{What This Study Adds to the Field:}

The present study demonstrates that time elapsed since symptoms onset to CAP diagnosis influences the systemic inflammatory profile differently for each cytokine. Patients with 3 or more days since symptoms onset showed lower levels of procalcitonin (PCT), interleukin (IL)-6 and IL-8, whereas those with less than 3 days had lower levels of C-reactive protein (CRP), even in those with sepsis. These findings provide new insight about the most useful window period for biomarker analyses: PCT within the first $48 \mathrm{~h}$ since onset of symptoms and CRP, IL-6 and IL-8 for those with 3 or more days. Onset of CAP symptoms should be considered at diagnosis to avoid underestimating the inflammatory response and for the future design of randomized clinical trials.

This article has an online data supplement, which is accessible from the online table of contents at www.atsjournals.org. 


\section{ABSTRACT}

Rationale. Assessment of the inflammatory response can help decision-making process when diagnosing community-acquired pneumonia (CAP), but there is a lack of information about the influence of time since onset of symptoms. We studied the impact of the number of days since onset of symptoms on inflammatory cytokines and biomarkers concentrations at CAP diagnosis in hospitalized patients.

Methods. We performed a secondary analysis in two prospective cohorts including 541 patients in the derivation cohort and 422 in the validation cohort. The time since onset of symptoms was self-reported and patients were classified as early presenters ( $<3$ days) and non-early presenters. Biomarkers (C-reactive protein and procalcitonin (PCT) in both cohorts) and cytokines in the derivation cohort (interleukins 1, 6, 8, 10, and tumor necrosis factor-alpha) were measured within 24 hours of hospital admission.

Results. In early presenters, C-reactive protein was significantly lower whereas procalcitonin, interleukin- 6 and 8 were higher. Non-early presenters showed significantly lower procalcitonin, interleukin-6, and interleukin-8 levels. In the validation cohort, CRP and PCT exhibited identical pattern: CRP levels were $36.4 \%$ greater in patients with $\geq 3$ days compared to those with $<3$ days in the derivation cohort and $38.2 \%$ in the validation cohort. PCT levels were $40 \%$ lower in patients with $\geq 3$ days in the derivation cohort and $56 \%$ in the validation cohort.

Conclusion. Time since symptoms onset modifies the systemic inflammatory profile at CAP diagnosis. That information has relevant clinical implications for management and it should taken into account in the design of future clinical trials.

Word count: 247

Keywords: pneumonia, inflammation, symptoms onset 


\section{INTRODUCTION}

Community-acquired pneumonia (CAP) remains an important infectious disease with a significant global burden, and is considered a major cause of sepsis worldwide $(1,2)$. Appropriate initial severity assessment and management at the emergency room (ER) can improve the prognosis, result in fewer complications, and reduce costs $(3,4)$.

In recent decades, physicians have made initial assessments of pneumonia based on symptoms, physical examination, and complementary data (e.g., x-rays or laboratory tests) supported by prognostic scales like the Pneumonia Severity Index, CURB65 $(5,6)$, or the more recent quick Sequential Organ Failure Assessment (qSOFA) (7). Over time, these scales have been combined with biomarkers and inflammatory cytokines to improve the decisionmaking process and to predict poor outcomes $(8,9)$. In the diagnostic process of lower respiratory tract infections and in sepsis, procalcitonin (PCT) levels have been used to decide both antibiotic initiation and its duration (10-13). Moreover, treatment may differ based on initial inflammatory biomarker levels, as corticosteroid treatment was found to reduce treatment failure in patients with high initial CRP levels (14).

The interest in knowing the different patterns of inflammation and their related factors has led to a better understanding of the immunopathogenic process that occurs in CAP (15-17). The natural course of the infection and its systemic inflammatory pattern prior to diagnosis is rather unknown, although presumably it can differ depending on the duration of the infection and the distinct kinetics of inflammatory cytokine and biomarkers. Our hypothesis was that time since onset of symptoms influences the systemic concentrations of inflammatory cytokines and biomarkers levels at CAP diagnosis, mainly during the first hours when bacterial growth is taking place and the host is mounting the inflammatory response. So far, there is a lack of published data about that aspect that we 
considered key for interpreting the initial inflammatory pattern in CAP.

Accordingly, we aimed to evaluate the influence of time since onset of symptoms on the initial levels of inflammatory cytokines and biomarkers at CAP diagnosis in hospitalized patients. Additionally, our findings were evaluated in a different cohort with data of biomarkers at CAP diagnosis. Some of the results of these studies have been previously reported in the form of an abstract $(18,19)$.

\section{PATIENTS AND METHODS}

\section{Design and Study Population}

The study involved secondary analyses of data from two prospective longitudinal cohorts. First cohort, or derivation cohort, was recruited at two tertiary-care university hospitals in Spain from 2004 to 2006 and from 2012 to 2015 (Hospital La Fe, Valencia; Hospital Clínic, Barcelona). Second cohort, or validation cohort, was obtained from a database of two different tertiary-care university hospitals in Spain from 2012 to 2015 (Hospital de Galdakao, Galdakao; Hospital de Mataró, Mataró). The local ethics committees approved the study, and either patients or their closest relatives provided written informed consent. The study was conducted in accordance with the Strengthening the Reporting of Observational Studies in Epidemiology (STROBE) guidelines (20).

CAP was diagnosed if new acute respiratory symptoms, signs, and compatible infiltrate(s) on chest $x$-ray were present. Exclusion criteria were age $<18$ years, other active infection, admission within prior 15 days, nursing-home residence, and if immunocompromised (e.g., transplant recipients, patients with malignancies, HIV+ patients, or treatment with $\geq 20 \mathrm{mg} /$ day of prednisone or equivalent for $>14$ days). We also excluded patients with chronic liver disease because C-reactive protein (CRP) is mainly produced in 
hepatocytes after stimulation by some interleukins (IL) $(21,22)$.

\section{Data Collection and Definitions}

We collected data on demographic characteristics and comorbidities (i.e., diabetes mellitus, respiratory, heart, liver, neurological, and renal diseases). The severity of disease at presentation was assessed with the Pneumonia Severity Index (PSI) and sepsis was defined according to the updated clinical criteria reported by the Sepsis-3 Task Force $(5,23)$. Antibiotic treatment before CAP diagnosis in the current episode was recorded.

The time, measured in days since the onset of CAP symptoms and/or signs until diagnosis at the ER, was self-reported by patients themselves or by close relatives during clinical interview. Any respiratory symptoms and/or signs (i.e., chest pain, cough, expectoration, dyspnea, chills, and temperature $\geq 37.8^{\circ} \mathrm{C}$ ) related to the acute process were considered. According to symptoms onset, patients were divided into two groups: "early presenters" if time was $<3$ days and "non-early presenters" if $\geq 3$ days. That threshold was selected taking into account that during the first 48 hours bacterial growth is rising and systemic inflammation is escalating as observed in pneumonia animal models (24-26).

Outcomes evaluated were length of stay and mortality during hospitalization and at 30 days following hospital admission.

\section{Microbiological Tests}

The following microbiological studies were carried out: paired blood cultures, urinary antigens for Legionella pneumophila and Streptococcus pneumoniae, sputum Gram stain (if $<10$ epithelial cells and >25 leukocytes per field; magnification $\times 100$ ) and culture, paired serological studies for Chlamydophila pneumoniae, Mycoplasma pneumoniae, Coxiella burnetii, and Legionella pneumophila. Invasive samples by bronchoscopy and/or pleurocentesis were obtained if required by the attending physician. 


\section{Study of Biomarkers and Cytokines}

Venous blood samples were obtained within the first 24 hours of hospital admission and processed to acquire serum, which was stored at $-80{ }^{\circ} \mathrm{C}$ until analysis. Determination of cytokines was made using an enzyme immunoassay (BioSource) according to the manufacturer's instructions. Cytokines were only analyzed in the derivation cohort. The cytokines of interest were IL-1, IL-6, IL-8, IL-10, and tumor necrosis factor-alpha (TNF- $\alpha$ ). Procalcitonin (PCT) levels were determined using an immunoluminometric technique (Liason Brahms PCT) with a detection limit of $0.03 \mathrm{ng} / \mathrm{mL}$. C-reactive protein (CRP) was detected using an immunoturbidimetric test (Bayer diagnostics) with a detection limit of $0.15 \mathrm{mg} / \mathrm{L}$. In the validation cohort, PCT levels were determined using an electrochemiluminiscence immunoassay in a Cobas 6000e autoanalyzer (Roche Diagnostics) with an analytical sensitivity of $0.02 \mathrm{ng} / \mathrm{mL}$ and coefficients of variation, obtained in routine (one run daily), of $3.26 \%(0.51 \mathrm{ng} / \mathrm{mL})$ and $4.72 \%(9.48 \mathrm{ng} / \mathrm{mL})$. CRP levels were measured using an inmunoturbidimetric method in a Cobas 6000c autoanalyzer (Roche Diagnostics) with an analytical sensitivity of $1 \mathrm{mg} / \mathrm{L}$ and coefficients of variation obtained in routine (one run daily) of $4.85 \%(9.33 \mathrm{mg} / \mathrm{L})$ and $5.61 \%(40.63 \mathrm{mg} / \mathrm{L})$.

\section{Statistical Analysis}

Statistical analyses were performed using IBM SPSS 20.0 software (SPSS, Chicago, III). Patients were grouped and compared with regard to classification as early or non-early presenters. Baseline characteristics, comorbidity, previous antibiotic treatment, prognostic scales, severity (i.e. PSI), and the presence of sepsis were analyzed and compared. Categorical variables were presented as $n(\%)$ and compared with the $\chi^{2}$ test, while continuous variables were presented as medians and interquartile ranges (IQR) and analyzed with the Mann-Whitney $U$ test. Values of $p<0.05$ were considered significant. 
Radar plots were built to illustrate the concentration of cytokines and biomarkers according to time since onset of symptoms.

\section{RESULTS}

\section{Patients' Baseline Characteristics}

We included 584 patients in the derivation cohort and 422 in the validation cohort (Figure 1). The median duration since onset of symptoms until CAP diagnosis in the ER was 5 days in both cohorts (IQR 3-7 days). 122 patients (22.6\%) in the derivation cohort and 82 $(20.6 \%)$ in the validation cohort had attended the ER within the first 48 hours of symptoms (early presenters). Early presenters were older, had more comorbidities, and greater initial CAP severity in both cohorts. By contrast, non-early presenters had more often received antibiotic treatment before admission. The most notable differences between the two cohorts were pneumococcal vaccination, previous antibiotic treatment and change in mental status (less frequent in the validation cohort). Longer length of stay was found in early presenters in the derivation cohort but not in the validation cohort. No significant differences in other outcomes were found when comparing the two cohorts (Table 1).

\section{Biomarkers and Cytokines Related to Time since Onset of Symptoms}

Derivation cohort. Biomarker and cytokine levels are depicted in Figure 2 according to duration of symptoms at CAP diagnosis in patients with or without previous antibiotic treatment. No significant differences were found for any of the biomarkers or cytokines with regard to previous antibiotic treatment (see Table E1 in the online supplement). CRP levels were highest in patients with $\geq 3$ days of symptoms, whereas PCT, IL-6, and IL-8 showed higher levels in patients with $<3$ days of symptoms (Table 2). Early presenters had 
significantly lower CRP concentrations and higher PCT, IL-6, and IL-8 concentrations. Figure 3 shows all biomarkers and cytokines expressed in deciles of concentrations in the derivation cohort in early and non-early presenters.

Validation cohort. Early presenters also showed significant lower levels of CRP in comparison to non-early presenters (Table 2). The median levels of CRP were $38.2 \%$ greater in patients with $\geq 3$ days compared to those with $<3$ days, and $36.4 \%$ in the derivation cohort. By contrast, higher levels of PCT were found in those patients with early presentation. The median levels of PCT were $40 \%$ lower in patients with $\geq 3$ days in comparison with those with $<3$ days in the derivation cohort and $56 \%$ in the validation cohort.

\section{Biomarkers and Cytokines by Initial Severity: PSI and Sepsis}

Derivation cohort. When we analyzed data according to severity, in patients with mild disease (PSI I-III) PCT and IL-6 levels were lower in those with longer duration of symptoms; by comparison, patients with more severe disease (PSI IV-V) and $<3$ days of symptoms had lower CRP levels (Table 3). Patients with sepsis showed significantly higher levels of CRP compared to those without sepsis. There were lower levels of CRP in patients with $<3$ days since onset of symptoms when compared to those with $\geq 3$ days, irrespective of the presence of sepsis (Figure 4a). PCT levels in early presenters with sepsis were higher compared to those without sepsis in the derivation cohort $(p<0.05)$ (Figure $4 b)$.

Validation cohort. In patients with mild disease (PSI I-III), significantly lower levels of CRP were found in early presenters, with a trend, that did not reach statistical significance, in those with PSI IV-V. No significant differences were found in PCT (Table 3). In sepsis, CRP levels showed a trend to lower levels in early presenters without reaching statistical 
significance (16.5 [8.5-26.9] vs 21.4 [10.6-30.5] mg/L, p: 0.092) (Figure 4a). With respect to PCT levels, early presenters with sepsis showed a trend toward higher levels without reaching statistical significance (2.75 [0.27-5.26] vs $1.3[0.27-5.26] \mathrm{ng} / \mathrm{mL}, \mathrm{p}: 0.100)$ (Figure 4b).

\section{DISCUSSION}

The main findings of our study are as follows: first, we showed that the inflammatory response at the time of CAP diagnosis was influenced by the time since onset of symptoms. Second, we showed that the CRP level was significantly lower in patients presenting $<3$ days since onset of symptoms, while PCT, IL-6, and IL-8 were already elevated. Third, we showed that PCT, IL-6, and IL-8 were significantly reduced after 3 days of symptoms, but that CRP was still raised; these findings were confirmed for PCT and CRP in the validation cohort. The inflammatory patterns were maintained in patients with sepsis in the derivation cohort and a similar trend was observed in the validation cohort. Based on these results, we believe that the initial biomarker levels at CAP diagnosis should be interpreted considering the number of days since the onset of CAP symptoms.

In this study, we have demonstrated that the inflammatory systemic response differs at the time of CAP diagnosis, specifically when many clinical decisions are made, depending on the number of days since symptoms onset. In the derivation cohort, the median time since symptom onset to CAP diagnosis was 5 days, with $22.6 \%$ of patients diagnosed within the first 48 hours, similar to prior publications (27), very similar to the percentage in the validation cohort. Patients who had more comorbidities, higher initial severity (PSI IV-V), and were older tended to present sooner at the ER in both cohorts. This may reflect their greater awareness of respiratory symptoms and the risk of poor evolution. 
The inflammatory profile in non-early presenters was characterized by lower expressions of PCT and proinflammatory cytokines, apart from CRP, compared to those patients with 3 days or less from onset of symptoms, probably because the more intense infection phase has ended. Our findings were corroborated in the validation cohort, even though the biomarker analysis methods were not identical. Our data could be explained by a depletion and exhaustion of biomarker production over time in the process of fighting microorganisms. To our knowledge, there are no comparable published data in patients, apart from the study by Calbo et al. who performed a small study in 32 adults with pneumococcal CAP, splitting them on early $(<48 \mathrm{~h})$ or late-comers (25). Dallaire et al., in a mouse model of pneumococcal pneumonia, determined that a plateau of bacterial growth was reached at 36 hours and that of inflammatory mediators at 84 hours post-infection, followed by a posterior bacterial load drop after 92 hours (24). Reyes et al., in a baboon animal pneumonia model, described that after a challenge with Streptococcus pneumoniae there is a rapid (24 hours) increase in serum proinflammatory cytokines and chemokines, which remain raised during 5-6 days, with a later rapid decline after antibiotic treatment $(26,28)$.

The systemic inflammatory pattern in patients diagnosed within $<3$ days of symptoms showed a greater inflammatory expression of IL-6, IL-8, and PCT, supporting the idea of a more robust early response during the first days except for CRP, which has slower kinetics (29). A delay of 48 hours in the peak levels of CRP with regard to IL-6 (main inducer of CRP production in hepatocytes) has been documented in animal models and healthy volunteers after IL-6 stimulation $(30,31)$. A similar profile was confirmed in the validation cohort with regard to CRP and PCT, despite the fact that PCT levels were slightly higher in that cohort compared to the derivation cohort. In fact, non-early presenters showed CRP 
levels $36.4 \%$ higher then the early presenters in the derivation cohort and $38.2 \%$ in the validation cohort. On the other hand, non early-presenters had levels of PCT $40 \%$ and $56 \%$ lower in the derivation and validation cohort respectively. After microorganisms enter the lung there is an early innate immune response provoking systemic inflammation in $24-48$ hours. Martínez-Olondris et al., in a piglet pneumonia model with methicillin-resistant Staphylococcus aureus, detected at 24 hours of inoculum an increase in systemic levels of IL6, IL-8 and TNF- $\alpha$ (32). CRP behaved differently, with levels increasing until day 3 and remaining sustained until day 7 , regardless of the use of prior antibiotics. Calbo et al. reported similar CRP results in early presenters ( $>48$ hours), concluding that they could be related to bacterial growth, as reported in animal models of pneumonia $(24,25)$. In the present study, we observed maximum CRP levels and a turning point on day 3.

The inflammatory pattern according to time since onset of CAP symptoms was also observed in the subset of patients with higher initial severities (PSI IV-V) in the derivation cohort. We observed the same trend in PSI IV-V patients, although without reaching statistical significant difference, in the validation cohort, probably due to a beta error. On the other hand, in sepsis, CRP levels were significantly lower in early presenters compared to non-early presenters, who had levels $40.3 \%$ higher in the derivation cohort. In contrast, PCT and IL-6 or IL-8 levels were significantly higher in early presenters. A similar trend was observed in patients with sepsis from the validation cohort with an increase in CRP of $30.3 \%$ and a decrease in PCT of $53.8 \%$ in non-early presenters compared to the early presenters.

The clinical impact of assessing inflammation and initial severity through biomarkers (mainly PCT and CRP) and cytokines has been investigated for the management of respiratory infections $(33,34)$. Our findings point out to the importance of that neglected factor to interpret biomarkers levels at CAP diagnosis. We highlight the possibility of 
underestimating the inflammatory response and, consequently, misclassifying disease severity depending on the biomarker or cytokine used. In a randomized clinical trial, Torres et al. reported that corticosteroid treatment added to antibiotics in CAP patients with high initial inflammation (CRP $>15 \mathrm{mg} / \mathrm{L}$ ) reduced treatment failure (14). Nevertheless, we can speculate that in patients diagnosed within the first 48 hours since onset of symptoms, CRP could underestimate inflammatory response because that biomarker is still in an increasing phase. Given our observations, duration of symptoms should also be considered in the design of future clinical trials evaluating the inflammatory response.

For the daily clinical practice at CAP diagnosis, we propose a simple useful recommendation: PCT (or IL-6, IL-8) is superior when assessing disease severity in patients with symptoms for $<3$ days, whereas CRP is a better choice in patients with symptoms for $\geq 3$ days. Noteworthy, cytokines and biomarkers levels found at diagnosis reflect the highest inflammatory profile reached during the CAP episode, because after antibiotic treatment their levels will rapidly - IL-6, IL-10, PCT- or more slowly-IL-8- decline (35).

Our study has some limitations. Notably, the time since symptom onset was selfreported (or reported by close relatives) and dependent on the subjective perception of symptoms, and will have been influenced by demographic, cultural, socioeconomic, tolerance, and another external factors (36). However, in this kind of clinical research there is no objective way to determine the exact onset of CAP infection, opposite to what occurs for other causes of sepsis (e.g., wounds) (37). In addition, we have no data about the first symptom to appear. In the case of influenza, oseltamivir is more effective during the first days after the onset of fever. It would be interesting to analyze these data in a prospective study (38). Another limitation is that microbiological testing was not systematically done to diagnose viruses. Indeed, it is known that the inflammatory response to viral infections, 
alone or combined with bacteria, has a different pattern to that shown for bacterial infections $(39,40)$. Our validation cohort has no cytokine data although we consider that for clinical purposes data on CRP and PCT are easily available in most hospitals.

\section{Conclusions}

In summary, these results highlight the influence of time since onset of symptoms until presentation on the interpretation of inflammatory markers in CAP. Patients who present $\geq 3$ days after onset of symptoms may have decreased levels of some biomarkers (e.g., PCT, IL-6, and IL-8), whereas in those diagnosed within the first $48 \mathrm{~h}$ the inflammatory response measured by CRP is still in an increasing phase, even in patients with more severe disease. Our findings have easy and rapid clinical translation at CAP diagnosis to avoid underestimation of host response: PCT (and/or IL-6, IL-8) investigation is recommended in patients with $\leq 48$ hours since onset of symptom, while CRP is better in patients with 3 days or more. Thus, we conclude that the inflammatory response must be interpreted taking into account the duration of symptoms in clinical assessment at CAP diagnosis and also when designing and conducting randomized clinical trials. 


\section{ACKNOWLEDGMENTS}

The authors would like to thank Luz Mimbiela and Alba Piró for their support, work and dedication to this project. Catia Cillóniz is recipient of ERS Short Term Fellowship and Postdoctoral Grant "Strategic plan for research and innovation in health-PERIS 2016-2020". 


\section{REFERENCES}

1. Feldman C, Anderson R. Community-acquired pneumonia: still a major burden of disease. Curr Opin Crit Care 2016;22:477-484.

2. Quan TP, Fawcett NJ, Wrightson JM, Finney J, Wyllie D, Jeffery K, Jones N, Shine B, Clarke L, Crook D, Walker AS, Peto TEA, Infections in Oxfordshire Research Database (IORD). Increasing burden of community-acquired pneumonia leading to hospitalisation, 1998-2014. Thorax 2016;71:535-42.

3. Youkee D, Hulme W, Roberts T, Daniels R, Nutbeam T, Keep J. Time Matters: Antibiotic Timing in Sepsis and Septic Shock. Crit Care Med 2016;44:e1016-e1017.

4. Daniel P, Rodrigo C, Mckeever TM, Woodhead M, Welham S, Lim WS. Time to first antibiotic and mortality in adults hospitalised with community-acquired pneumonia: a matched-propensity analysis. Thorax 2015;34:887-92.

5. Fine MJ, Auble TE, Yealy DM, Hanusa BH, Weissfeld LA, Singer DE, Coley CM, Marrie TJ, Kapoor WN. A Prediction Rule to Identify Low-Risk Patients with CommunityAcquired Pneumonia. N EnglJ Med 1997;336:243-250.

6. Lim WS, van der Eerden MM, Laing R, Boersma WG, Karalus N, Town GI, Lewis SA, Macfarlane JT. Defining community acquired pneumonia severity on presentation to hospital: an international derivation and validation study. Thorax 2003;58:377-82.

7. Ranzani OT, Prina E, Menéndez R, Ceccato A, Cilloniz C, Méndez R, Gabarrus A, Barbeta E, Bassi GL, Ferrer M, Torres A. New Sepsis Definition (Sepsis-3) and Community-acquired Pneumonia Mortality. A Validation and Clinical Decision-Making Study. Am J Respir Crit Care Med 2017;196:1287-1297.

8. Menéndez R, Martínez R, Reyes S, Mensa J, Filella X, Marcos M a, Martínez A, Esquinas C, Ramirez P, Torres A. Biomarkers improve mortality prediction by 
prognostic scales in community-acquired pneumonia. Thorax 2009;64:587-591.

9. Ito $\mathrm{A}$, Ishida $\mathrm{T}$, Tachibana $\mathrm{H}$, Ito $\mathrm{Y}$, Takaiwa $\mathrm{T}$. Serial procalcitonin levels for predicting prognosis in community-acquired pneumonia. Respirology 2016;21:1459-1464.

10. Schuetz P, Briel M, Christ-Crain M, Stolz D, Bouadma L, Wolff M, Luyt C-E, Chastre J, Tubach F, Kristoffersen KB, Wei L, Burkhardt O, Welte T, Schroeder S, Nobre V, Tamm M, Bhatnagar N, Bucher HC, Mueller B. Procalcitonin to guide initiation and duration of antibiotic treatment in acute respiratory infections: an individual patient data meta-analysis. Clin Infect Dis 2012;55:651-62.

11. Oliveira CF, Botoni FA, Oliveira CRA, Silva CB, Pereira HA, Serufo JC, Nobre V. Procalcitonin versus C-reactive protein for guiding antibiotic therapy in sepsis: a randomized trial. Crit Care Med 2013;41:2336-43.

12. Aliberti S, Giuliani F, Ramirez J, Blasi F. How to choose the duration of antibiotic therapy in patients with pneumonia. Curr Opin Infect Dis 2015;28:177-184.

13. Nobre V, Harbarth S, Graf J-D, Rohner P, Pugin J. Use of procalcitonin to shorten antibiotic treatment duration in septic patients: a randomized trial. Am J Respir Crit Care Med 2008;177:498-505.

14. Torres A, Sibila O, Ferrer M, Polverino E, Menendez R, Mensa J, Gabarrús A, Sellarés J, Restrepo MI, Anzueto A, Niederman MS, Agustí C. Effect of corticosteroids on treatment failure among hospitalized patients with severe community-acquired pneumonia and high inflammatory response. JAMA 2015;313:677.

15. Lorenzo M, Moret I, Sarria B, Cases E, Cortijo J, Méndez R, Molina J, Gimeno A, Menéndez R. Lung inflammatory pattern and antibiotic treatment in pneumonia. Respir Res 2015;7:16-15.

16. Bosmann M, Ward PA. The Inflammatory Response in Sepsis. Trends Immunol 
2014;34:129-136.

17. Martinez R, Menéndez R, Reyes S, Polverino E, Cilloniz C, Martinez A. Factors associated with inflammatory cytokine patterns in community-acquired pneumonia. Eur Respir J 2011;37:393-399.

18. Mendez R, Menendez R, Posadas T, Piro A, Cilloniz C, Ceccato A, Torres A. Kinetics Of Biomarkers Depends On Onset Of Symptoms In Community-Acquired Pneumonia. at <http://www.atsjournals.org/doi/pdf/10.1164/ajrccmconference.2017.195.1_MeetingAbstracts.A6859>.

19. Méndez R, Menéndez R, Amara-Elori I, Piró A, Cilloniz C, Ceccato A, Torres A. Interpretation of biomarkers at emergency department depends on onset of symptoms in community-acquired pneumonia. Eur Respir J 2017;50:PA4520.

20. von Elm E, Altman DG, Egger M, Pocock SJ, Gøtzsche PC, Vandenbroucke JP, STROBE Initiative. The Strengthening the Reporting of Observational Studies in Epidemiology (STROBE) statement: guidelines for reporting observational studies. Lancet 2007;370:1453-1457.

21. Kushner I, Feldmann G. Control of the acute phase response. Demonstration of Creactive protein synthesis and secretion by hepatocytes during acute inflammation in the rabbit. J Exp Med 1978;148:466-77.

22. Eklund CM. Proinflammatory cytokines in CRP baseline regulation. Adv Clin Chem 2009;48:111-36.

23. Singer M, Deutschman CS, Seymour CW, Shankar-Hari M, Annane D, Bauer M, Bellomo R, Bernard GR, Chiche JD, Hotchkiss RS11, Levy MM, Marshall JC, Martin GS, Opal SM, Rubenfeld GD, van der Poll T, Vincent JL AD. The Third International Consensus Definitions for Sepsis and Septic Shock (Sepsis-3). JAMA 2016;315:801- 
810.

24. Dallaire F, Ouellet N, Bergeron Y, Turmel V, Gauthier M, Simard M, Bergeron M. Microbiological and inflammatory factors associated with the development of pneumococcal pneumonia. J Infect Dis 2001;184:292-300.

25. Calbo E, Alsina M, Rodríguez-Carballeira M, Lite J, Garau J. The impact of time on the systemic inflammatory response in pneumococcal pneumonia. Eur Respir J 2010;35:614-8.

26. Reyes LF, Restrepo MI, Hinojosa CA, Soni NJ, Shenoy AT, Gilley RP, Gonzalez-Juarbe N, Noda JR, Winter VT, de la Garza MA, Shade RE, Coalson JJ, Giavedoni LD, Anzueto A, Orihuela CJ. A Non-Human Primate Model of Severe Pneumococcal Pneumonia. In: Jeyaseelan S, editor. PLoS One 2016;11:e0166092.

27. Sanz F, Restrepo MI, Fernández-Fabrellas E, Cervera Á, Briones ML, Novella L, Aguar MC, Chiner E, Fernandez JF, Blanquer J. Does prolonged onset of symptoms have a prognostic significance in community-acquired pneumonia? Respirology 2014;10731079.doi:10.1111/resp.12346.

28. Reyes LF, Restrepo MI, Hinojosa CA, Soni NJ, Anzueto A, Babu BL, Gonzalez-Juarbe N, Rodriguez AH, Jimenez A, Chalmers JD, Aliberti S, Sibila O, Winter VT, Coalson JJ, Giavedoni LD, Dela Cruz CS, Waterer GW, Witzenrath M, Suttorp N, Dube PH, Orihuela CJ. Severe Pneumococcal Pneumonia Causes Acute Cardiac Toxicity and Subsequent Cardiac Remodeling. Am J Respir Crit Care Med 2017;196:609-620.

29. Menéndez R, Cavalcanti M, Reyes S, Mensa J, Martinez R, Marcos MA, Filella X, Niederman M, Torres A. Markers of treatment failure in hospitalised community acquired pneumonia. Thorax 2008;63:447-452.

30. Pepys MB, Hirschfield GM. C-reactive protein: a critical update. J Clin Invest 
2003;111:1805-12.

31. Volanakis JE. Human C-reactive protein: expression, structure, and function. Mol Immunol 2001;38:189-97.

32. Martínez-Olondris P, Sibila O, Agustí C, Rigol M, Soy D, Esquinas C, Piñer R, Luque N, Guerrero L, Quera MÁ, Marco F, de la Bellacasa JP, Ramirez J, Torres A. An experimental model of pneumonia induced by methicillin-resistant Staphylococcus aureus in ventilated piglets. Eur Respir J 2010;36:901-6.

33. Schuetz P, Christ-Crain M, Thomann R, Falconnier C, Wolbers M, Widmer I, Neidert S, Fricker T, Blum C, Schild U, Regez K, Schoenenberger R, Henzen C, Bregenzer T, Hoess C, Krause M, Bucher HC, Zimmerli W, Mueller B, for the ProHOSP Study Group. Effect of procalcitonin-based guidelines vs standard guidelines on antibiotic use in lower respiratory tract infections. JAMA 2009;302:1059.

34. Almirall J, Bolíbar I, Toran P, Pera G, Boquet X, Balanzó X, Sauca G. Contribution of CReactive Protein to the Diagnosis and Assessment of Severity of Community-Acquired Pneumonia. Chest 2004;125:1335-1342.

35. Paats MS, Bergen IM, Hanselaar WEJJ, Groeninx van Zoelen EC, Hoogsteden HC, Hendriks RW, van der Eerden MM. Local and systemic cytokine profiles in nonsevere and severe community-acquired pneumonia. Eur Respir J 2013;41:1378-1385.

36. Gavidia R, Fuentes SL, Vasquez R, Bonilla M, Ethier M-C, Diorio C, Caniza M, Howard SC, Sung L. Low socioeconomic status is associated with prolonged times to assessment and treatment, sepsis and infectious death in pediatric fever in El Salvador. PLoS One 2012;7:e43639.

37. Busch NA, Zanzot EM, Loiselle PM, Carter EA, Allaire JE, Yarmush ML, Warren HS. A model of infected burn wounds using Escherichia coli O18:K1:H7 for the study of 
gram-negative bacteremia and sepsis. Infect Immun 2000;68:3349-51.

38. Treanor JJ, Hayden FG, Vrooman PS, Barbarash R, Bettis R, Riff D, Singh S, Kinnersley N, Ward P, Mills RG, for the US Oral Neuraminidase Study Group for the UONS. Efficacy and Safety of the Oral Neuraminidase Inhibitor Oseltamivir in Treating Acute Influenza. JAMA 2000;283:1016.

39. Menéndez R, Sahuquillo-arce JM, Reyes S, Martínez R, Polverino E, Cillóniz C, Córdoba JG, Montull B, Torres A. Cytokine activation patterns and biomarkers are influenced by microorganisms in community-acquired pneumonia. Chest 2012;141:1537-1545.

40. Self WH, Balk RA, Grijalva CG, Williams DJ, Zhu Y, Anderson EJ, Waterer GW, Courtney DM, Bramley AM, Trabue C, Fakhran S, Blaschke AJ, Jain S, Edwards KM, Wunderink RG. Procalcitonin as a Marker of Etiology in Adults Hospitalized With CommunityAcquired Pneumonia. Clin Infect Dis 2017;65:183-190. 
Table 1. Baseline characteristics according to time since onset of symptoms

\begin{tabular}{|c|c|c|c|c|c|c|}
\hline & \multicolumn{3}{|c|}{ Derivation Cohort } & \multicolumn{3}{|c|}{ Validation Cohort } \\
\hline & $\begin{array}{l}<3 \text { days } \\
122(22.6)\end{array}$ & $\begin{array}{l}\geq 3 \text { days } \\
419(77.4)\end{array}$ & $p$-value & $\begin{array}{l}<3 \text { days } \\
82(20.6)\end{array}$ & $\begin{array}{l}\geq 3 \text { days } \\
316(79.4)\end{array}$ & $p$-value \\
\hline \multicolumn{7}{|l|}{ Demographic } \\
\hline Age (years) & $75(64-81)$ & $69(55-78)$ & $<0.001$ & $75(64-84)$ & $67(51-79)$ & 0.001 \\
\hline Men & $93(76.2)$ & $268(64)$ & 0.011 & $54(65.9)$ & $196(62)$ & 0.523 \\
\hline Pneumococcal vaccine & $16(13.1)$ & $42(10)$ & 0.331 & $1(1.2)$ & $14(4.4)$ & 0.060 \\
\hline Influenza vaccine & $56(45.9)$ & $159(37.9)$ & 0.114 & $32(39)$ & $117(37)$ & 0.149 \\
\hline Alcohol abuse & $3(3.8)$ & $6(2.4)$ & 0.500 & $5(6.1)$ & $12(3.8)$ & 0.891 \\
\hline Current smokers & $16(20)$ & $64(25.1)$ & 0.351 & $14(17.1)$ & $56(17.7)$ & 0.351 \\
\hline \multicolumn{7}{|l|}{$\begin{array}{l}\text { Comorbidities and } \\
\text { treatments }\end{array}$} \\
\hline Respiratory disease & $51(42.5)$ & $143(34.4)$ & 0.103 & $22(26.8)$ & $75(23.7)$ & 0.561 \\
\hline Neurological disease & $33(27)$ & $56(13.5)$ & $<0.001$ & $17(21)$ & 47 (14.9) & 0.186 \\
\hline Heart failure & $31(25.4)$ & $59(14.1)$ & 0.003 & $22(26.8)$ & $69(21.8)$ & 0.337 \\
\hline Renal disease & $12(9.8)$ & $34(8.1)$ & 0.549 & $13(15.9)$ & $26(8.3)$ & 0.039 \\
\hline Diabetes Mellitus & $36(29.5)$ & $84(20)$ & 0.027 & $13(15.9)$ & $58(18.4)$ & 0.598 \\
\hline Previous pneumonia & $47(38.5)$ & $100(23.9)$ & 0.001 & $20(24.7)$ & $32(10.3)$ & 0.001 \\
\hline Inhaled corticosteroids & $29(23.8)$ & $89(21.2)$ & 0.552 & $22(26.8)$ & 60 (19) & 0.118 \\
\hline $\begin{array}{l}\text { Previous antibiotic } \\
\text { treatment }\end{array}$ & $24(19.7)$ & $162(38.7)$ & $<0.001$ & $9(11)$ & $64(20.3)$ & 0.053 \\
\hline \multicolumn{7}{|l|}{ Symptoms } \\
\hline Fever & $93(76.2)$ & $326(77.8)$ & 0.714 & $53(72.6)$ & $212(70.7)$ & 0.744 \\
\hline Shivering & $85(69.7)$ & $276(66.8)$ & 0.556 & $39(52.7)$ & $117(39.9)$ & 0.047 \\
\hline Cough & 84 (68.9) & $348(83.7)$ & $<0.001$ & $48(62.3)$ & $250(81.7)$ & $<0.001$ \\
\hline
\end{tabular}




\begin{tabular}{lllllll} 
Expectoration & $42(52.5)$ & $148(58.3)$ & 0.364 & $33(47.1)$ & $169(57.7)$ & 0.111 \\
Dyspnea & $76(62.3)$ & $265(63.4)$ & 0.824 & $36(46.8)$ & $129(42.9)$ & 0.538 \\
Chest pain & $44(36.4)$ & $176(42.4)$ & 0.234 & $25(34.7)$ & $83(29)$ & 0.346 \\
Change in mental status & $26(21.5)$ & $44(10.7)$ & 0.002 & $6(8.7)$ & $13(4.6)$ & 0.181 \\
Digestive symptoms & $25(20.5)$ & $86(20.6)$ & 0.984 & $5(7.2)$ & $31(11)$ & 0.354 \\
$\begin{array}{l}\text { Initial severity } \\
\text { Sepsis }\end{array}$ & $69(61.6)$ & $211(54.2)$ & 0.167 & $44(53.7)$ & $162(51.3)$ & 0.699 \\
$\begin{array}{l}\text { Pneumonia Severity } \\
\text { Index class }\end{array}$ & & & & & \\
$\quad$ I & $9(7.4)$ & $58(13.8)$ & & $8(9.8)$ & $63(19.9)$ & \\
\multicolumn{1}{|l|}{} & $18(14.8)$ & $87(20.8)$ & & $10(12.2)$ & $47(14.9)$ & \\
$\quad$ III & $22(18)$ & $109(26)$ & 0.002 & $18(22)$ & $77(24.4)$ & 0.037 \\
$\quad$ IV & $52(42.6)$ & $125(29.8)$ & & $28(34.1)$ & $92(29.1)$ &
\end{tabular}

\section{Microbiology}

\begin{tabular}{|c|c|c|c|c|c|c|}
\hline Etiologic diagnosis & $52(44.1)$ & $185(44.5)$ & 0.938 & $23(28)$ & $101(32.1)$ & 0.119 \\
\hline $\begin{array}{l}\text { Streptococcus } \\
\text { pneumoniae }\end{array}$ & $31(25.4)$ & 79 (18.9) & 0.113 & $19(23.8)$ & $75(23.8)$ & 0.991 \\
\hline Legionella pneumophila & $0(0)$ & $26(6.2)$ & 0.005 & $1(1.2)$ & $9(2.8)$ & 0.401 \\
\hline Atypical bacteria & $5(4.1)$ & $38(9.1)$ & 0.076 & $2(3.1)$ & $4(1.5)$ & 0.397 \\
\hline Polymicrobial & $9(7.5)$ & $44(10.6)$ & 0.323 & $0(0)$ & $10(3.7)$ & 0.110 \\
\hline Bacteremia & $14(11.5)$ & $31(7.4)$ & 0.151 & 9 (15.5) & $27(13.3)$ & 0.666 \\
\hline
\end{tabular}

\section{Outcomes}

\begin{tabular}{lcccccc} 
Length of stay (days) & $8(6-10)$ & $7(5-10)$ & 0.012 & $4(3-8)$ & $4(3-7)$ & 0.912 \\
In-hospital mortality & $4(3.3)$ & $18(4.3)$ & 0.617 & $5(6.1)$ & $11(3.2)$ & 0.282 \\
30 days mortality & $6(4.9)$ & $20(4.8)$ & 0.948 & $5(6.1)$ & $12(3.8)$ & 0.359 \\
\hline
\end{tabular}

Data presented as $\mathrm{n}(\%)$ or median (IQR) 
Table 2. Biomarkers according to time since onset of symptoms

\begin{tabular}{|c|c|c|c|c|c|c|}
\hline & \multicolumn{3}{|c|}{ Derivation Cohort } & \multicolumn{3}{|c|}{ Validation Cohort } \\
\hline & $\begin{array}{c}<3 \text { days } \\
\text { N: } 122\end{array}$ & $\begin{array}{c}\geq 3 \text { days } \\
\text { N: } 419\end{array}$ & $p$-value & $\begin{array}{c}\leq 3 \text { days } \\
\mathrm{N}: 82\end{array}$ & $\begin{array}{c}>3 \text { days } \\
\text { N: } 316\end{array}$ & $p$-value \\
\hline CRP (mg/L) & $13.2(7.8-23.3)$ & 18 (9.9-27.9) & 0.005 & $13.6(6.6-23.5)$ & $18.8(9.2-29.3)$ & 0.006 \\
\hline PCT (ng/mL) & $0.5(0.1-3.4)$ & $0.3(0.1-1.5)$ & 0.023 & $0.9(0.2-5)$ & $0.4(0.1-2.3)$ & 0.028 \\
\hline TNF- $\alpha(\mathrm{pg} / \mathrm{mL})$ & $16(4-32)$ & $14(3.8-30)$ & 0.439 & - & - & - \\
\hline $\mathrm{IL}-1$ (pg/mL) & $4(0.5-10)$ & $3(0.5-16)$ & 0.595 & - & - & - \\
\hline IL-6 (pg/mL) & $97(22-238.8)$ & $53.5(17-162)$ & 0.012 & - & - & - \\
\hline $\mathrm{IL}-8(\mathrm{pg} / \mathrm{mL})$ & $15(7-28)$ & $11(2.7-20.1)$ & 0.001 & - & - & - \\
\hline IL-10 (pg/mL) & $2.6(1-11)$ & $2.6(0-11)$ & 0.670 & - & - & - \\
\hline
\end{tabular}

Data presented as median (IQR) 
Table 3. Biomarkers according to time since onset of symptoms and initial severity

\begin{tabular}{|c|c|c|c|c|c|c|}
\hline & \multicolumn{3}{|c|}{ Derivation Cohort } & \multicolumn{3}{|c|}{ Validation Cohort } \\
\hline & $<3$ days & $\geq 3$ days & 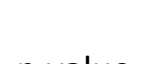 & $<3$ days & $\geq 3$ days & \\
\hline & $\mathrm{N}: 122$ & $\mathrm{~N}: 419$ & $\rho$-value & $N: 82$ & $N: 316$ & $\rho$-value \\
\hline PSI I-III & $49(16.2)$ & $254(83.8)$ & & $36(16.1)$ & 187 (83.9) & \\
\hline $\mathrm{CRP}(\mathrm{mg} / \mathrm{L})$ & $16(7.8-24.3)$ & $17.4(8.3-27)$ & 0.394 & $12.7(6.2-22.7)$ & $19.1(9.3-30)$ & 0.016 \\
\hline PCT (ng/mL) & $0.3(0.1-2.1)$ & $0.2(0.1-0.8)$ & 0.005 & $0.4(0.1-1.1)$ & $0.3(0.1-1.3)$ & 0.562 \\
\hline TNF- $\alpha(\mathrm{pg} / \mathrm{mL})$ & $14(3.8-23)$ & $12(3.8-24.5)$ & 0.985 & - & - & - \\
\hline IL-1 (pg/mL) & $2(0.5-12)$ & $2.9(0.5-12)$ & 0.762 & - & - & - \\
\hline IL-6 (pg/mL) & $60(18-153.2)$ & $36.6(14-133)$ & 0.186 & - & - & - \\
\hline IL-8 (pg/mL) & $13(6-18)$ & $8(2.7-15)$ & 0.046 & - & - & - \\
\hline IL-10 (pg/mL) & $2.2(2-7)$ & $2.2(0-9.3)$ & 0.809 & - & - & - \\
\hline PSI IV-V & $73(30.7)$ & $165(69.3)$ & & $46(26.7)$ & $126(73.3)$ & \\
\hline CRP (mg/L) & $13(6.6-22.4)$ & $19(12-30)$ & 0.001 & $16.1(7.3-23.5)$ & $18.5(8.5-28.7)$ & 0.133 \\
\hline РCT (ng/mL) & $0.7(0.1-4.6)$ & $0.6(0.2-2.9)$ & 0.851 & $2.8(0.3-7.2)$ & $1.2(0.2-4.9)$ & 0.081 \\
\hline TNF- $\alpha(\mathrm{pg} / \mathrm{mL})$ & $19.5(6-37)$ & $18(3.8-44)$ & 0.832 & - & - & - \\
\hline $\mathrm{IL}-1$ (pg/mL) & $4(1.4-10)$ & $4(0.5-18)$ & 0.782 & - & - & - \\
\hline IL-6 (pg/mL) & $122.5(35-391)$ & $82.3(23-286.7)$ & 0.274 & - & - & - \\
\hline IL-8 (pg/mL) & $18.5(8-35)$ & $14(4-31.6)$ & 0.142 & - & - & - \\
\hline IL-10 (pg/mL) & $3(0-12)$ & $3(0-15.1)$ & 0.914 & - & - & - \\
\hline
\end{tabular}

Data presented as $\mathrm{n}(\%)$ or median (IQR) 


\section{Figure Legends:}

Figure 1. Study flowchart. A: Derivation cohort; B: Validation cohort.

Figure 2. Biomarker concentrations (expressed as medians) according to time since onset of symptoms and previous antibiotic.

Figure 3. Radar plot of biomarkers according to time since onset of symptoms. Numbers express the deciles of biomarker concentrations. $A:<3$ days; $B: \geq 3$ days.

Figure 4. Biomarker concentrations (expressed as medians) according to time since onset of symptoms and sepsis. NS: Not significant; A: C-reactive protein; B: procalcitonin. 
A)

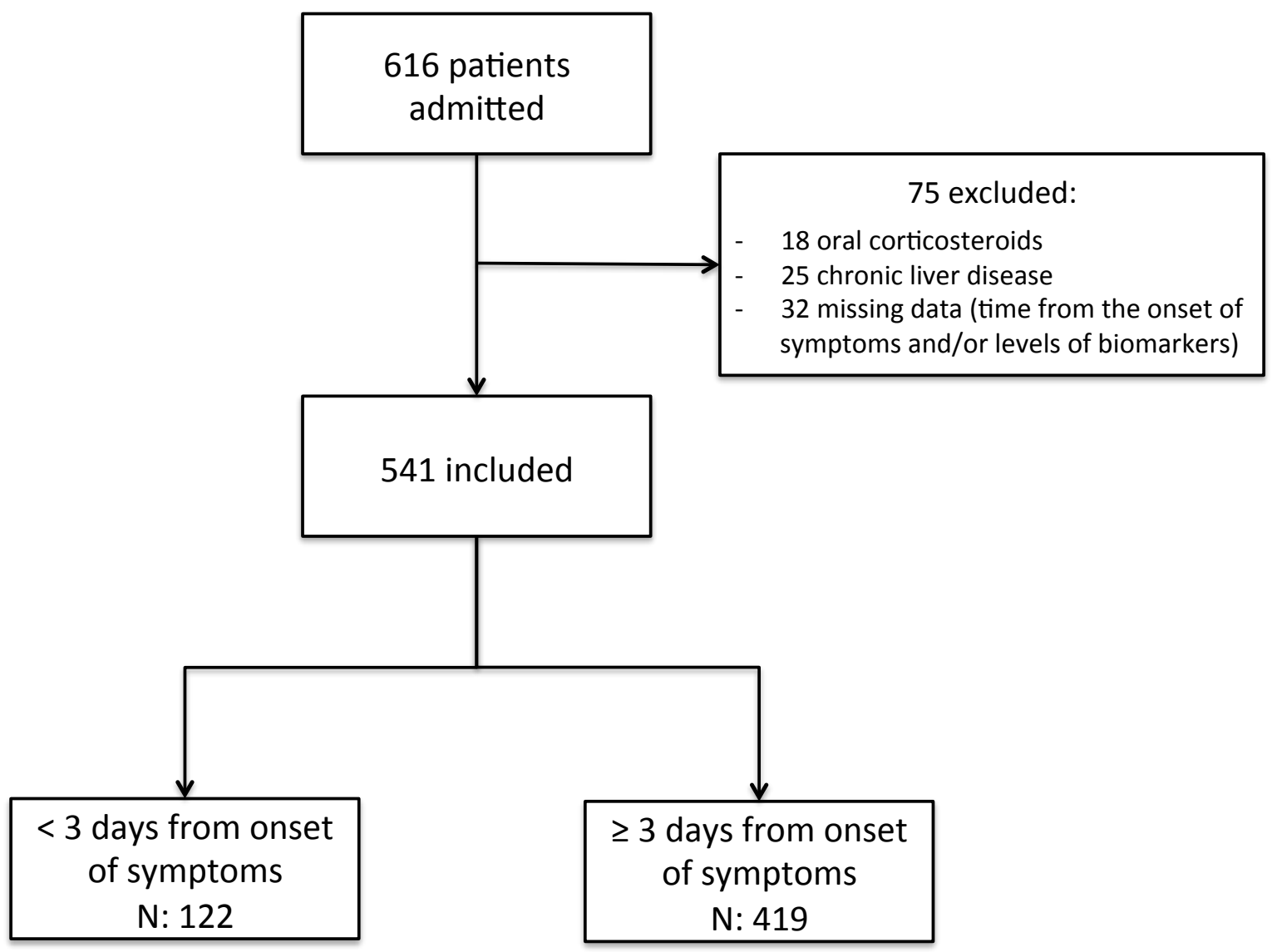

B)

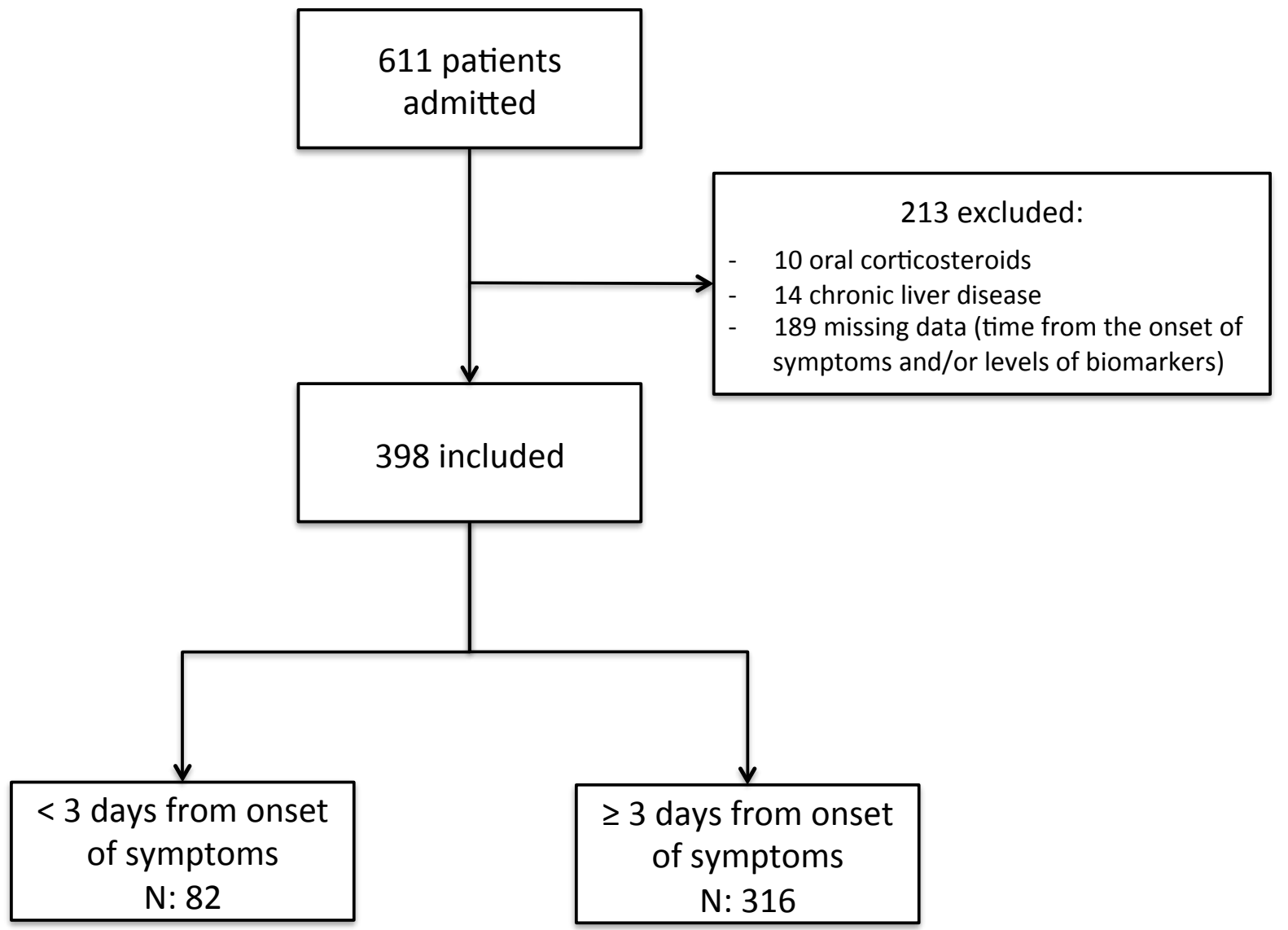



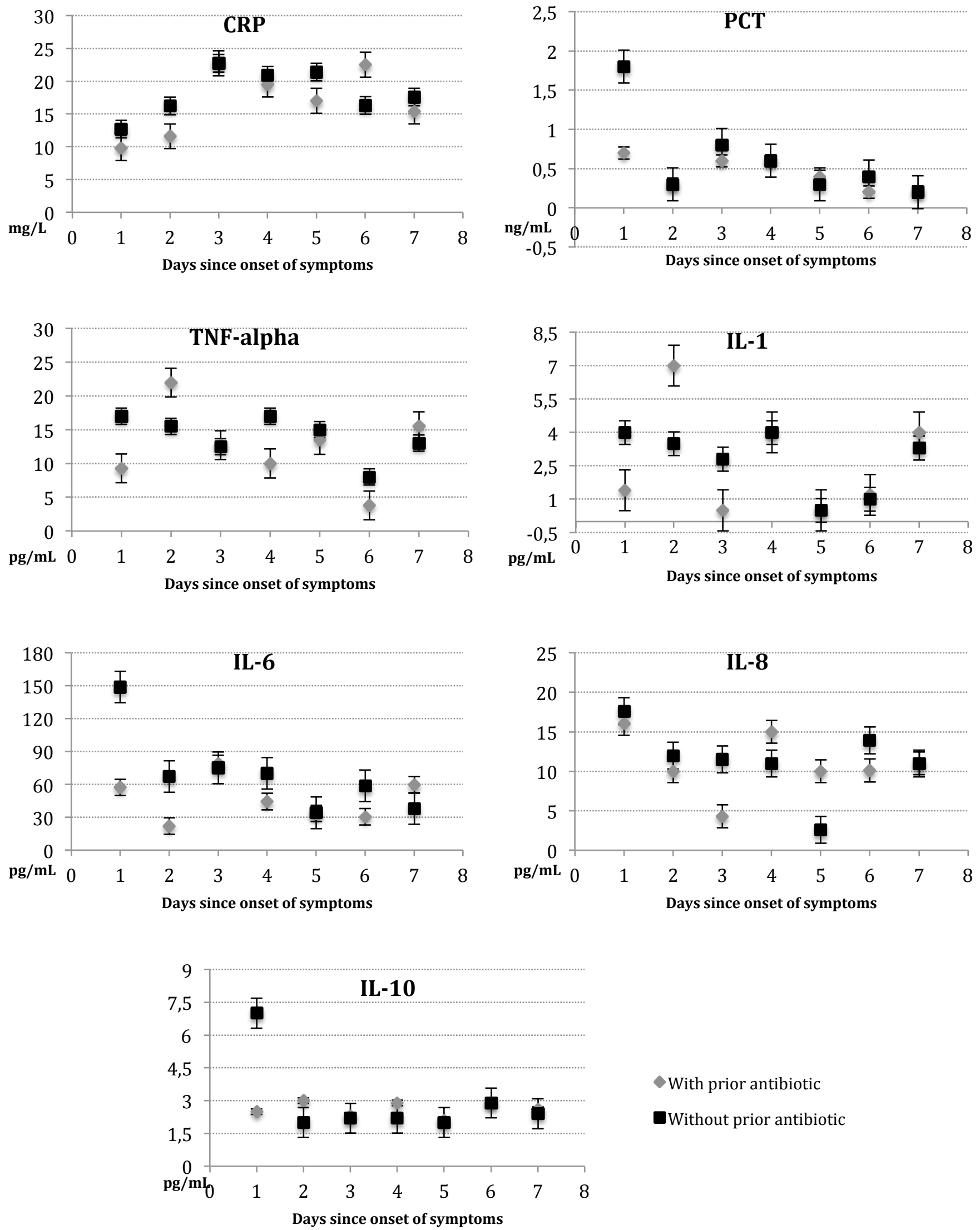

With prior antibiotic

Without prior antibiotic 
A)

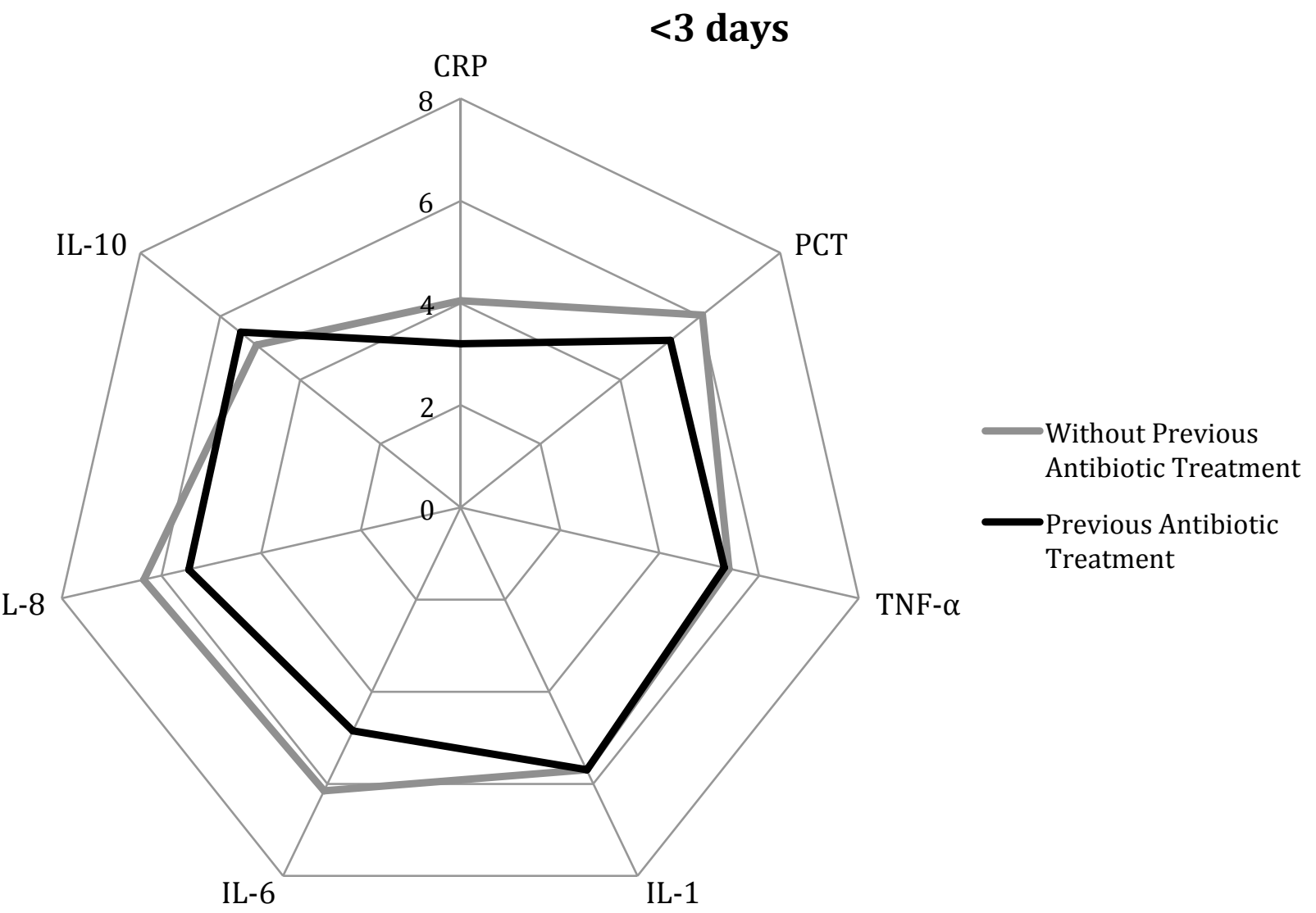

B)

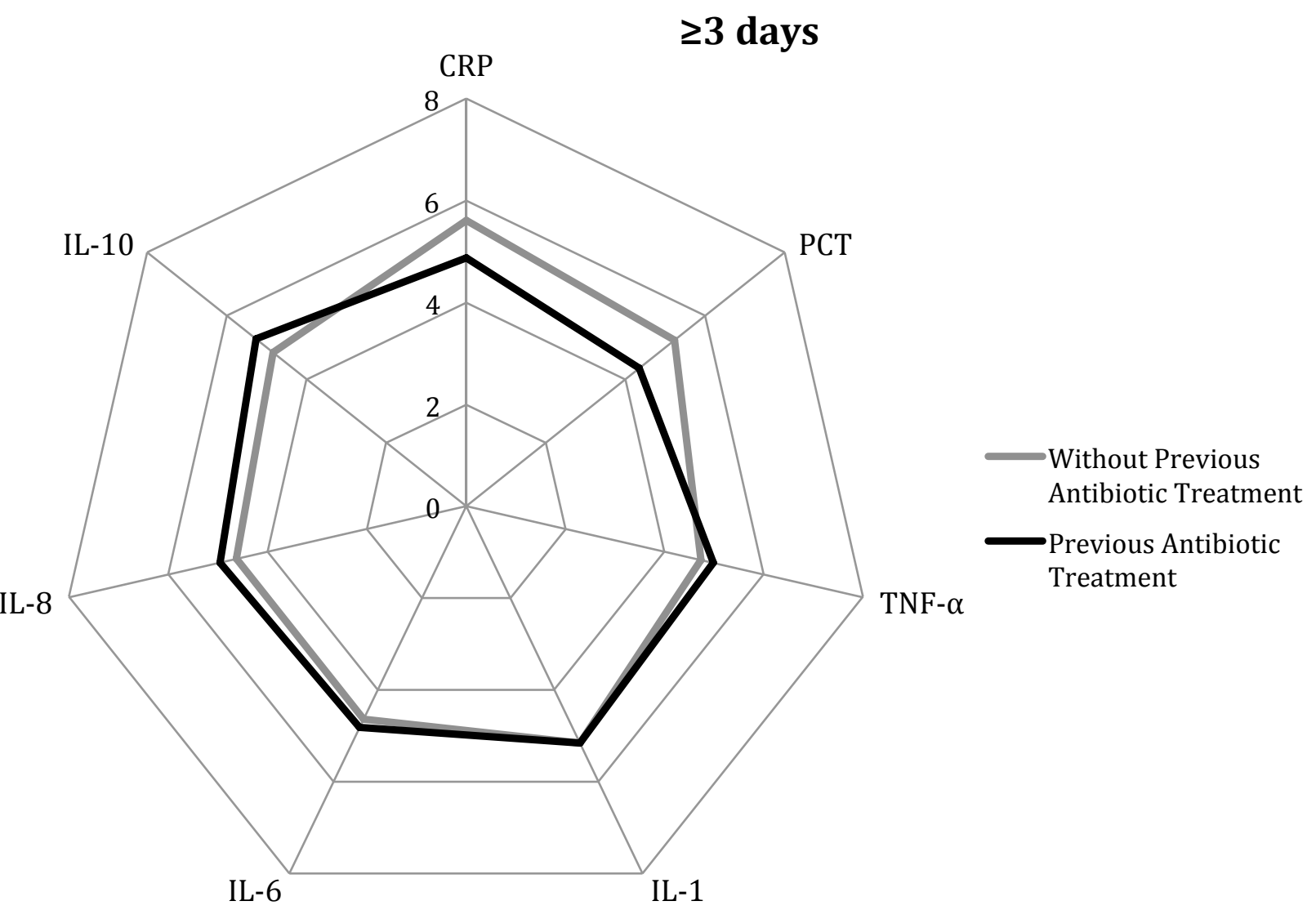



A)

\section{CRP}

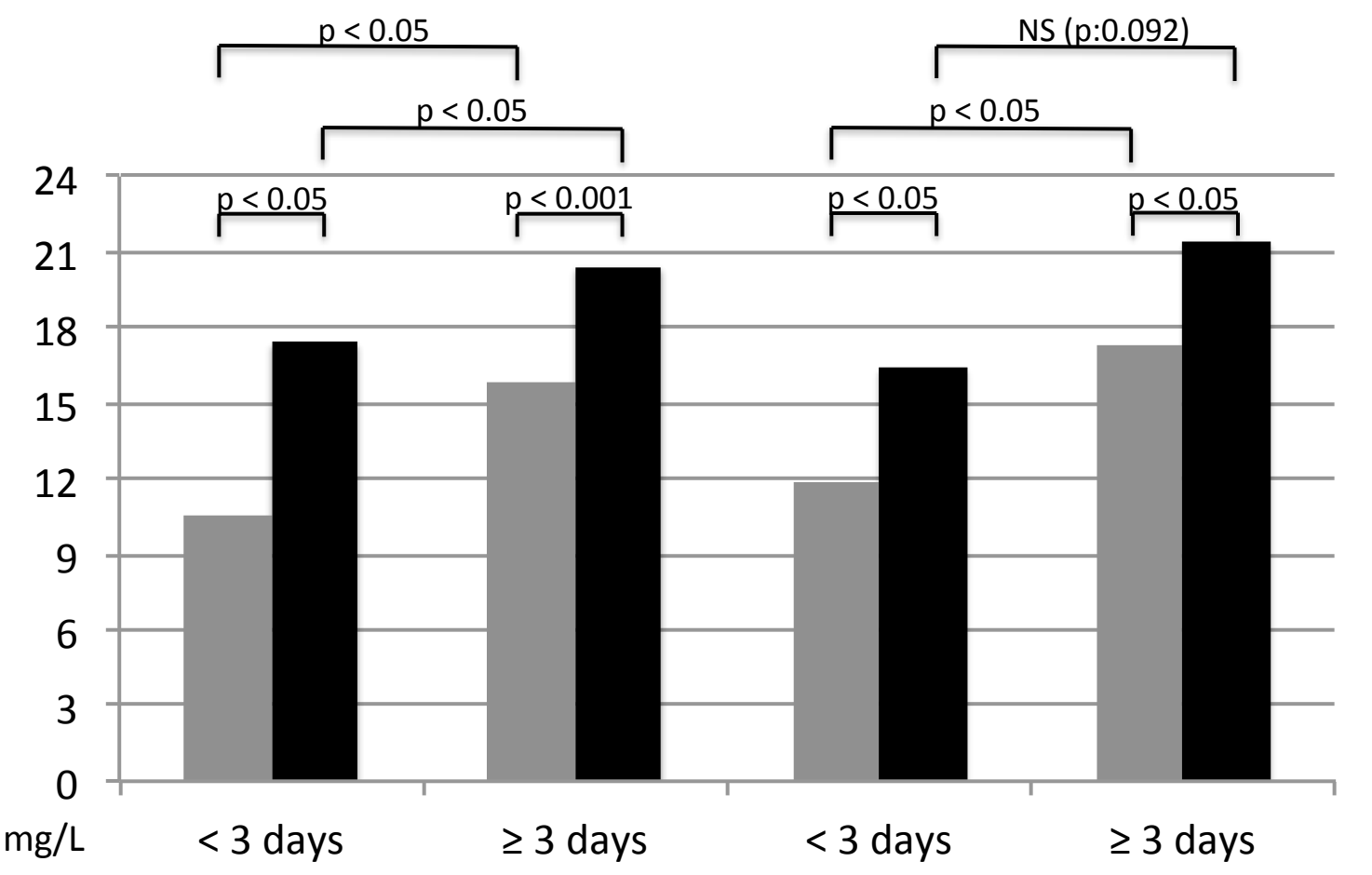

Absence of sepsis

Presence of sepsis

Derivation Cohort

Validation Cohort

B)

\section{PCT}

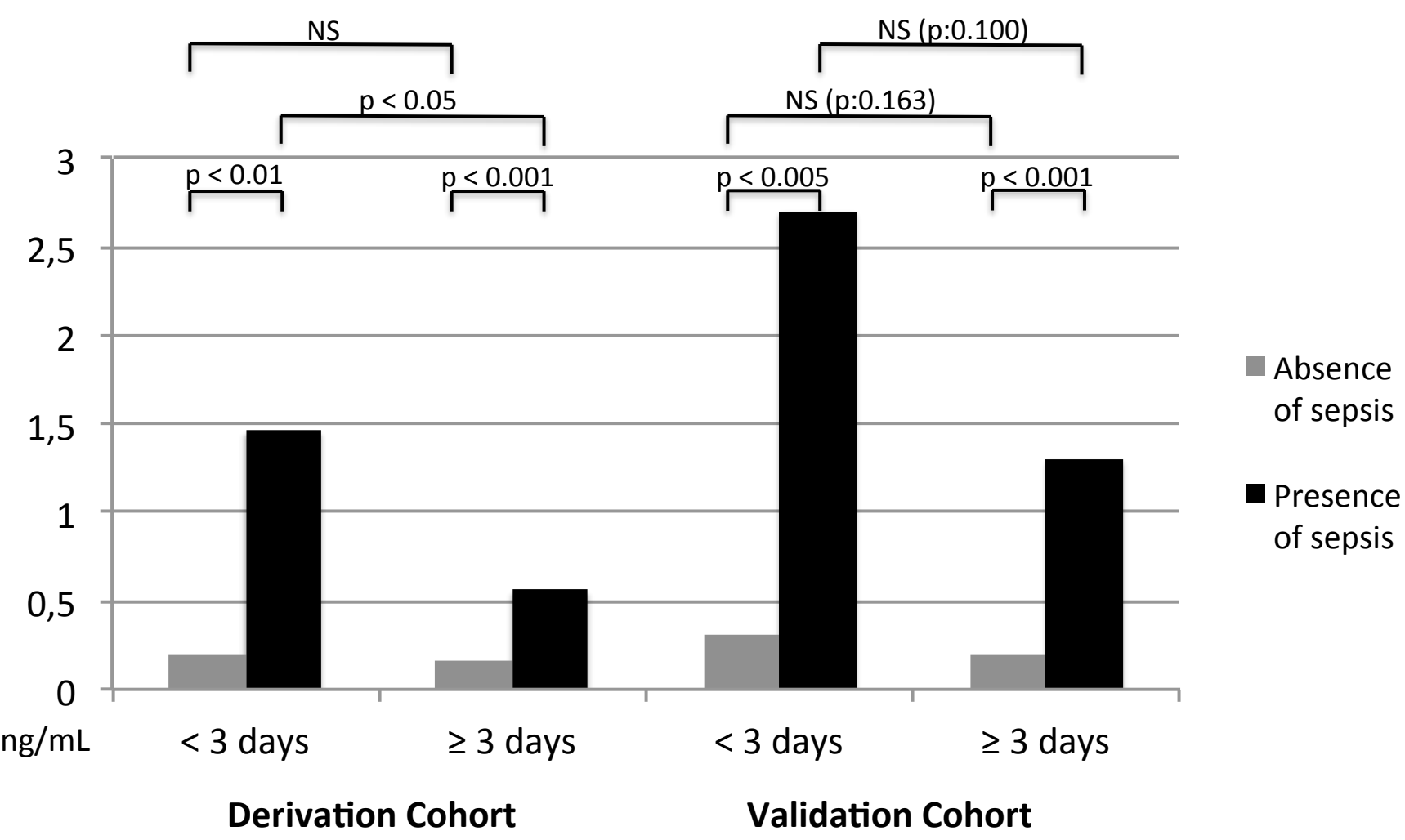


Table E1. Biomarkers according to previous antibiotic treatment.

\begin{tabular}{|c|c|c|c|c|c|c|}
\hline \multicolumn{4}{|c|}{ Derivation Cohort } & \multicolumn{3}{|c|}{ Validation Cohort } \\
\hline \multicolumn{7}{|c|}{ With previous antibiotic treatment } \\
\hline & $\begin{array}{c}<3 \text { days } \\
\mathrm{N}: 24\end{array}$ & $\begin{array}{l}\geq 3 \text { days } \\
\mathrm{N}: 162\end{array}$ & $p$-value & $\begin{array}{c}<3 \text { days } \\
\mathrm{N}: 9\end{array}$ & $\begin{array}{c}\geq 3 \text { days } \\
\mathrm{N}: 64\end{array}$ & $p$-value \\
\hline CRP & $13.2(7.8-23.3)$ & $18(9.9-27.9)$ & 0.071 & $12.6(10.4-18.4)$ & $14.34(10.4-18.4)$ & 0.973 \\
\hline PCT & $0.5(0.1-3.4)$ & $0.3(0.1-1.5)$ & 0.117 & $0.24(0.08-0.31)$ & $0.15(0.06-0.46)$ & 0.632 \\
\hline TNF- $\alpha$ & $16(4-32)$ & $14(3.8-30)$ & 0.978 & & & \\
\hline IL-1 & $4(0.5-10)$ & $3(0.5-16)$ & 0.934 & & & \\
\hline IL-6 & $97(22-238.8)$ & $53.5(17-162)$ & 0.916 & & & \\
\hline IL-8 & $15(7-28)$ & $11(2.7-20.1)$ & 0.426 & & & \\
\hline IL-10 & $2.6(1-11)$ & $2.6(0-11)$ & 0.748 & & & \\
\hline \multicolumn{7}{|c|}{ Without previous antibiotic treatment } \\
\hline & $\begin{array}{c}<3 \text { days } \\
\mathrm{N}: 98\end{array}$ & $\begin{array}{l}\geq 3 \text { days } \\
\mathrm{N}: 257\end{array}$ & $p$-value & $\begin{array}{c}<3 \text { days } \\
\mathrm{N}: 73\end{array}$ & $\begin{array}{l}\geq 3 \text { days } \\
\mathrm{N}: 252\end{array}$ & $p$-value \\
\hline CRP & $14.1(8.0-24.3)$ & $19.1(10.1-29.6)$ & 0.011 & $13.6(5.7-25.1)$ & $21(9.8-30.9)$ & 0.001 \\
\hline РCT & $0.64(0.11-3.94)$ & $0.37(0.09-2.02)$ & 0.193 & $1.3(0.23-5.22)$ & $0.76(0.16-4.23)$ & 0.095 \\
\hline TNF- $\alpha$ & $16.5(5-30)$ & $13.1(3.8-29)$ & 0.339 & & & \\
\hline IL-1 & $4(0.53-10)$ & $3(0.5-16)$ & 0.572 & & & \\
\hline IL-6 & $103.6(36-239)$ & $50.7(17-184)$ & 0.013 & & & \\
\hline IL-8 & $15.5(7-30)$ & $10.7(2.7-20)$ & 0.002 & & & \\
\hline IL-10 & $2.6(1-10.4)$ & $2.2(0-11)$ & 0.759 & & & \\
\hline
\end{tabular}

Data presented as median (IQR) 